\title{
Alleviating the infertility of an acid sulphate soil by using ground basalt with or without lime and organic fertilizer under submerged conditions
}

\begin{abstract}
A study was conducted into the alleviation of the infertility of an acid sulphate by using ground basalt with or without ground magnesium limestone (GML) and organic fertilizer. Fresh soils were treated with the amendments and subjected to two cycles of submergence and drying. The soil was dominated by kaolinite, mica and smectite. The untreated soil $\mathrm{pH}$ was $<3.5$ and solution Al was high. GML application at 4 tha- 1 was able to increase $\mathrm{pH}$ and subsequently reduced $\mathrm{Al}$ toxicity sufficiently to allow for rice growth. After 4 months of submergence, the $\mathrm{pH}$ of the sample treated with $4 \mathrm{t}$ ground basalt ha-1 had increased from $3 \cdot 61$ to $3 \cdot 94$, with concomitant decrease of Al. In the same cycle, the soil $\mathrm{pH}$ increase was much higher (reaching 5.22). Ground basalt is thus comparable with GML as an acid soil ameliorant. Within the experimental period, the ground basalt had mostly disintegrated and dissolved. The solution $\mathrm{pH}$ had further increased (to 5.94) in the second cycle because of dissolution of more ground basalt. This means that it takes time for ground basalt to completely dissolve and consequently supply $\mathrm{Ca}, \mathrm{Mg}, \mathrm{K}$ and $\mathrm{P}$ to the growing crop in the field. Applying $0 \cdot 25 \mathrm{t}$ organic fertilizer ha -1 into the soil had no significant effect on either $\mathrm{pH}$ or Al. This form of organic matter (compost) contains essential nutrients. It is recommended that $4 \mathrm{t}$ ground basalt should be applied in combination with $0 \cdot 25 \mathrm{t}$ organic fertilizer ha-1 a few months ahead of the growing season for maximal benefit. This study showed that ground basalt can be effectively used to ameliorate highly acidic soils.
\end{abstract}

Keyword: Acid sulphate soil; Aluminium; Ground basalt; Organic fertilizer; Rice; Malaysia; Rice culture 